\title{
Treatment for Maxillary Hypoplasia in Skeletal Class III Patient
}

Govind R Suryawanshi ${ }^{{ }^{*}}$, Koshi Philip ${ }^{2}$ and Sreejith Kumar ${ }^{2}$

${ }^{1}$ Yashodeep Clinic, Latur, Maharashtra, India

${ }^{2}$ Department of Orthodontics, Trivandrum, Kerala, India

*Corresponding author: Dr. Govind R Suryawanshi, Yashodeep clinic, Opposite to Tahsil Office, Miragi Netralaya, Main Road, Latur, Maharashtra, India, Tel: +919860371813; E-mail: dr.govindsuryawanshi@yahoo.com

Rec Date: Mar 11, 2014; Acc Date: Sep 12, 2014; Pub Date: Sep 14, 2014

Copyright: @ 2014 Suryawanshi GR, et al., This is an open-access article distributed under the terms of the Creative Commons Attribution License, which permits unrestricted use, distribution, and reproduction in any medium, provided the original author and source are credited.

\begin{abstract}
Objective: To present skeletal class III patient treated with protraction face mask and bonded rapid maxillary expander in order to demonstrate the effects of face mask and bonded rapid maxillary expander on maxillary hypoplasia skeletal class III patient.

Materials and methods: The patient was reported with skeletal class III malocclusion. The patient was 11 year 3 month old boy and his treatment duration was 13 months. Bonded rapid maxillary expander was placed on maxillary posterior teeth. Rapid maxillary expander activation was done for one week once daily. Orthopedic force of $500 \mathrm{gm}$ per side, 30 degree downward and forward from the occlusal plane was applied 12 to 14 hours per day. There after face mask therapy was started and continued for 13 months.
\end{abstract}

Results: Treatment resulted in significant forward displacement of the maxilla. Side effects such as labial tipping of the upper incisors, extrusion of the upper molars, clockwise rotations of the mandibular plane, and bite opening, were minimal.

Conclusion: Face mask with bonded rapid maxillary expander can be an effective treatment modality for maxillary hypoplasia in skeletal class III patient with minimal unwanted side effects.

Keywords: Maxillary protraction; Face mask; RME

\section{Introduction}

Facemask therapy is the most frequently used treatment protocol for skeletal malocclusion type of anomaly in orthodontic patients. The protraction facemask has been used to stimulate sutural growth at the circum-maxillary suture sites in growing patients with mild to moderate maxillary hypoplasia [1]. To transmit the orthopedic force from the protraction facemask to the maxilla, intraoral devices such as a labiolingual arch, quad helix, and bonded rapid maxillary expansion have been used. Intentionally ankylosed primary canines, osseointegrated implants and orthodontic miniscrews have been used as skeletal anchorage for protraction facemask therapy [2,3], Treatment with a facemask therapy results in a combination of forward movement of the maxilla, clockwise rotation of mandible, and forward movement of the upper incisors with retrusion of the lower incisors [4,5], Therefore labial inclined maxillary incisors and/or a vertical facial growth pattern would be contraindications for facemask therapy with tooth-borne anchorage. The purpose of this case report is to present skeletal class III patient with Face mask and rapid maxillary expander and to demonstrate the effect of facemask therapy on maxillary hypoplasia in this patient.

\section{Case Report}

The patient reported with maxillary hypoplasia and he was 11 year 3 month old boy. He presented with concave facial profile (Figure 1), anterior crossbite (3 $\mathrm{mm}$ reverse overjet), partially erupted 14 , overretained upper right deciduous canine and upper left deciduous canine (Figure 2). Cephalogram showed retrusive maxilla (Figure 3 and Figure 4). Cephalometric analysis (Figure 7) showed skeletal Class III malocclusion with maxillary hypoplasia (ANB, $-2^{\circ}$; A to N perp, -7 $\mathrm{mm}$ ), steep mandibular plane angle (FMA, $34^{\circ}$ ), and a skeletal age in the pubertal growth spurt according to the cervical vertebrae maturation index CVMI, stage 3 [6].

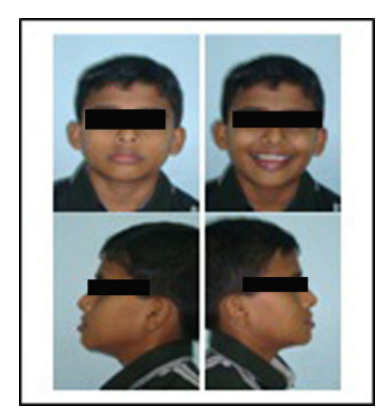

Figure 1: Pre treatment extra oral photographs 


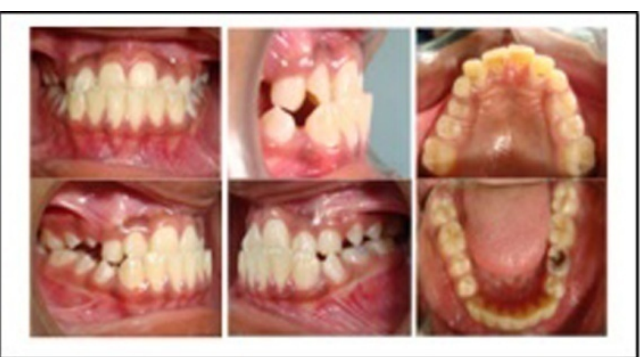

Figure 2: Pre treatment intra oral photographs

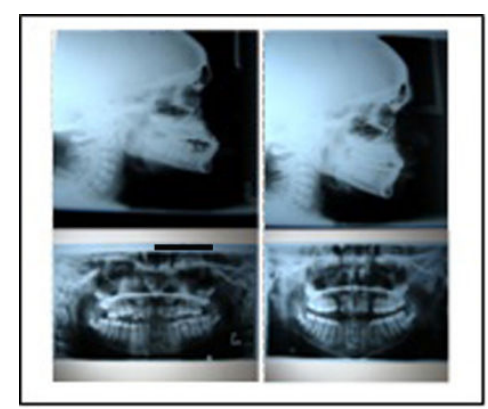

Figure 3: Lateral cephalograms and Orthopantomographs - Pre treatment -left and post treatment - right

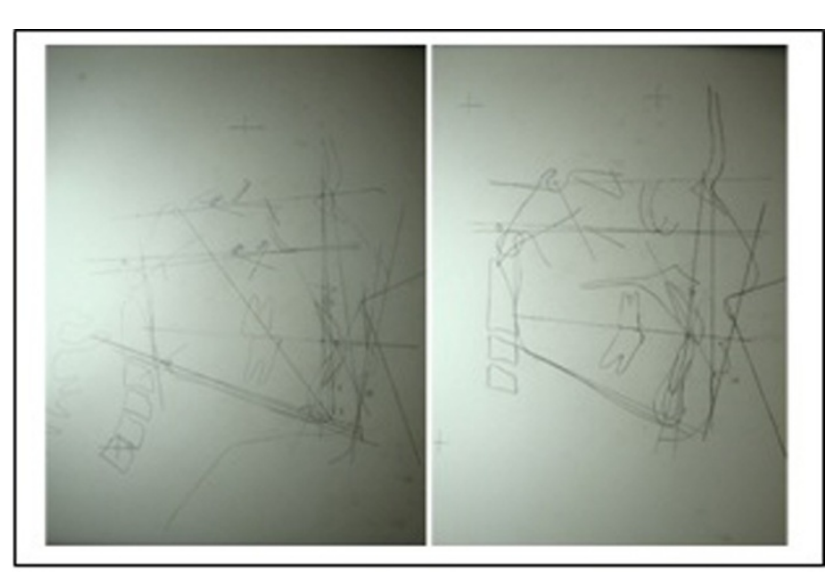

Figure 4: Tracing of lateral cephalograms - Pre treatment - left and post treatment - right

The protocol of Face mask and rapid maxillary expander therapy is as follows: the expander was specially designed to have hooks in the canine area for the attachments of the elastics. The rapid maxillary expander appliance was bonded on posterior teeth segment. Initially after an hour of bonding, the rapid maxillary expander appliance was activated for two 90 degree turns. Then appliance was activated once daily. Following the occurrence of a median diastema, the orthopedic force of 500 gm per side was applied for 12 to 14 hours per day by face mask therapy (Figure 5). Force applied direction and angulation was $30^{\circ}$ downward and forward from the occlusal plane in order to decrease the counterclockwise rotation of the upper occlusal plane. It is recommended to overcorrect the malocclusion into positive overjet and a slight Class II canine and molar relationship. Pretreatment and post-treatment photographs along with lateral cephalogram and orthopantomograms were taken and lateral cephalograms were traced and analyzed both before and after facemask therapy was completed. The treatment duration was 13 months.

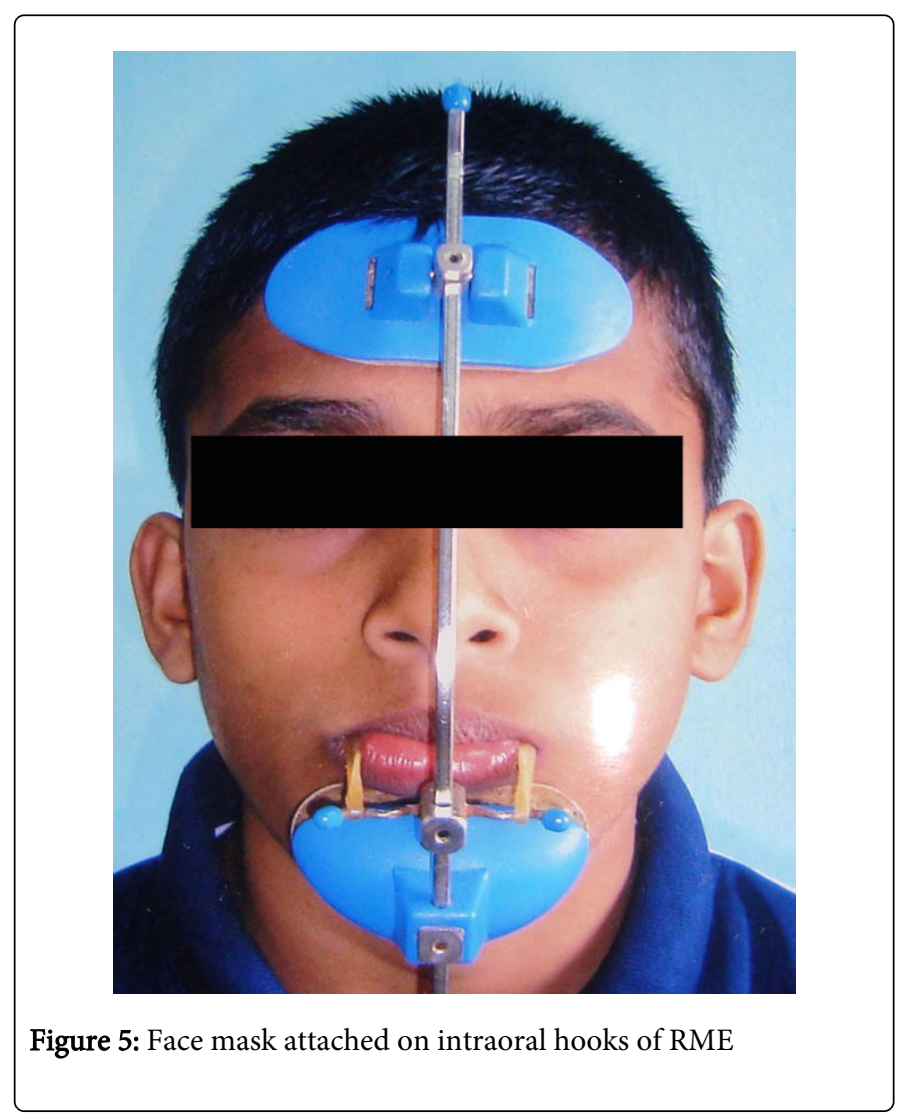

\section{Treatment Results}

After 13 months of facemask therapy, there was significant forward movement of the maxilla. Cephalometric findings were (A to $\mathrm{N}$ perpendicular, changed from -7 to $-4 \mathrm{~mm}$ ). The ANB angle was changed from $-2^{\circ}$ to $0^{\circ}$, No counterclockwise rotation of the occlusal plane angle (remained $16^{\circ}$ ) was interpreted to mean that there was almost no side effect such as extrusion of the upper molars. FMA was decreased by $2^{\circ}$, no labial tipping of the upper incisors (U1 to SN, remained $103^{\circ}$ ). The clinical findings were facial esthetic improvement (Figure 6), Class II canine and molar relationship, normal overbite, and overjet were obtained (Figure 7). Pre treatment and post treatment lateral cephalogram's superimposition on cranial base showed the skeletal changes (Figure 8). Pre treatment and post treatment lateral cephalogram's superimposition on maxilla and mandible showed the dental changes (Figure 9). 
Citation: Suryawanshi GR, Philip K, Kumar S (2014) Treatment for Maxillary Hypoplasia in Skeletal Class III Patient. Dentistry 4: 262. doi: $10.4172 / 2157-7633.1000262$

Page 3 of 5

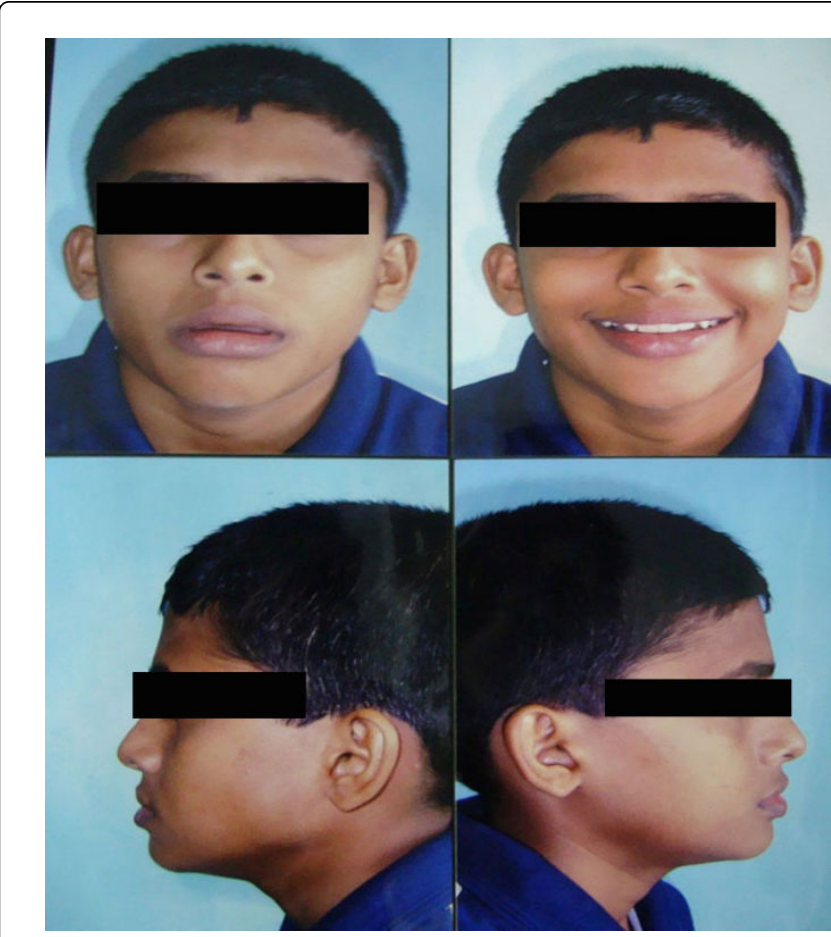

Figure 6: Post treatment extra oral photographs

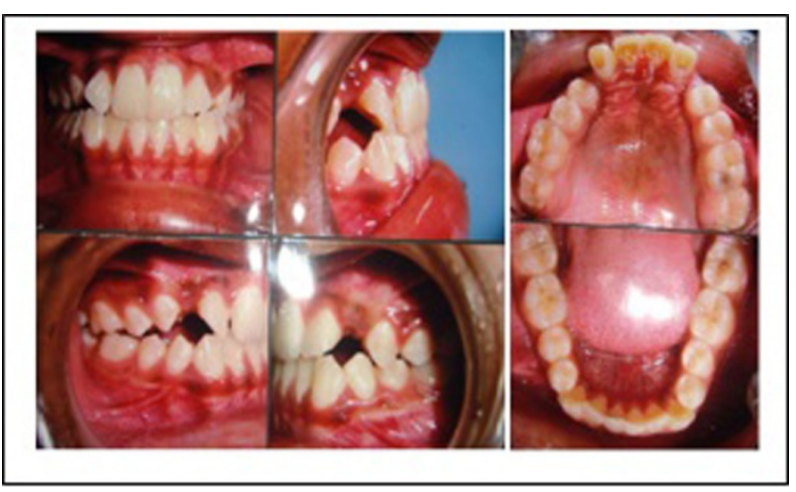

Figure 7: Post treatment intra oral photographs

\section{Discussion}

Maxillary hypoplasia in class III skeletal malocclusion is one of the cause for producing structural imbalance, functional inefficiency and esthetic disharmony. Face mask therapy for early growing age in adolescence helps to prevent this problem and eliminates the psychological problems in adolescence and the patient family. The literature reports that the facemask achieves approximately $1.5 \mathrm{~mm}$ to $2 \mathrm{~mm}$ of maxillary advancement with 6 months to 12 months of facemask wear, but this treatment protocol requires patient compliance and is not indicated in adult patients, in whom growth is complete $[7,8]$. Hereditary malocclusion should be diagnosed properly before starting of face mask therapy.

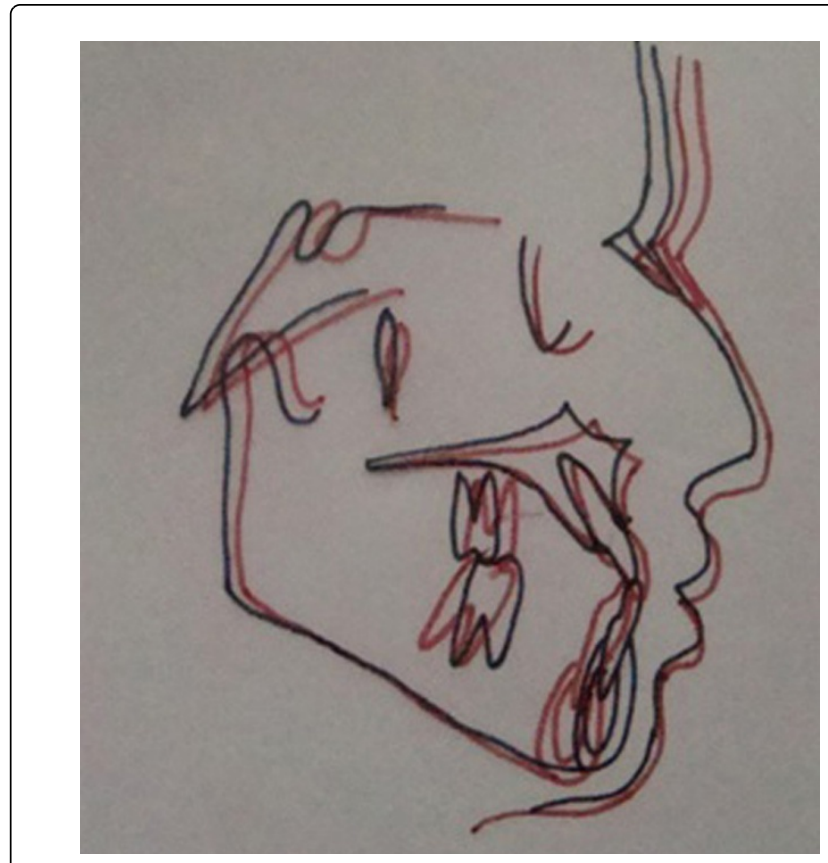

Figure 8: Pre treatment and post treatment lateral cephalogram's superimposition on cranial base showing the skeletal changes

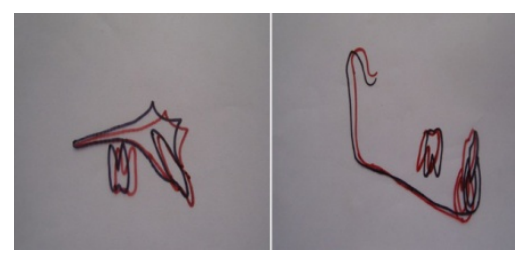

Figure 9: Pre treatment and post treatment lateral cephalogram's superimposition on maxilla and mandible showing the dental changes

Expansion of the maxilla before or during protraction of the maxilla has been performed to facilitate protraction by disarticulating the circum-maxillary sutures and initiating a cellular response in these sutures. Baik reported that there was more forward movement in the maxilla when protraction was in conjunction with rapid maxillary expander compared with protraction without rapid maxillary expander [7].

There are numerous articles that advocate the protraction therapy at an early stage [9-11] because the palatomaxillary suture becomes highly interdigitated with increasing age, it becomes difficult to disarticulate the palatal bone from the pterygoid process [12]. After the pubertal growth peak, side effects such as tooth movement and/or mandibular rotation rather than maxillary protraction are likely to be the major response to treatment [13].

In cases of untreated Class III malocclusion with maxillary hypoplasia, Shanker et al. [14], reported that point A came forward only $0.2 \mathrm{~mm}$ over a 6 -month period. With conventional facemask therapy, Kim et al. [15] from meta-analysis, reported that it produced $0.9 \mathrm{~mm}$ to $2.9 \mathrm{~mm}$ advancement of the point A. So [16] insisted that 
Page 4 of 5

the effect of protraction facemask therapy on the maxilla was two thirds skeletal and one third dental changes. In our cases a similar treatment protocol was used, the amount of maxillary advancement was $2 \mathrm{~mm}$.

Treatment with protraction headgears has shown a greater effect than in the present study concerning the reduction of skeletal Class III relations in terms of enlarged ANB angles. Macdonald et al. [17] and Takada et al. [18] achieved increases of $3.4^{\circ}$ and $3.6^{\circ}$ within 1 year, respectively; Chong et al. [19] observed a mean enlargement of $2^{\circ}$ within 2 years. The corresponding cephalometric value in the present study was $2^{\circ}$.

Wits values increased by $2 \mathrm{~mm}$, which is similar to the finding of 1.9 $\mathrm{mm}$ reported by Chong et al. [19]. However, Macdonald etal [17] found that some of the sagittal effects achieved with face mask were lost in the follow-up period when no treatment was performed. While the effects achieved are smaller with exclusively removable appliances, findings obtained in control groups have clearly demonstrated that they are able to induce minor improvements and to counteract the progression of Class III abnormalities.

The upper incisors position remained same. The overjet changes by $+5 \mathrm{~mm}$, similar to the values recorded by Chong et al. [19] after continuous treatment with protraction headgears were observed. The patient sample analyzed in the present study revealed only a small degree of maxillary rotation. Our finding of posterior rotation of the mandible is in keeping with similar results obtained in numerous previous studies investigating various modified versions of the facemask $[20,21]$.

The direction of force vector was $30^{\circ}$ downward and forward from the occlusal plane. Tanne et al. [22] and Miyasaka-Hiraga et al. [23] reported that downward and forward force produced uniform stretch and translatory repositioning of the nasomaxillary complex in an anterior direction. Negligible changes of the palatal plane angle, FMA, and mandibular plane to SN angle were observed. Upper lip position was observed to be moved forwardly significantly (Table 1).

\begin{tabular}{|l|l|l|}
\hline \multirow{2}{*}{ Variables } & \multicolumn{2}{l|}{ Observations in Patient } \\
\cline { 2 - 3 } & pre & post \\
\hline $\begin{array}{l}\text { Anteroposterior skeletal relationship } \\
\text { SNA }^{\circ}\end{array}$ & 78 & 80 \\
\hline SNB $^{\circ}$ & 80 & 80 \\
\hline ANB $^{\circ}$ & -2 & 0 \\
\hline A to N Perpendicular (mm) & -7 & -4 \\
\hline Pog to N pendicular (mm) & -4 & -3 \\
\hline Wits appraisal (mm) & -1 & 1 \\
\hline $\begin{array}{l}\text { Vertical skeletal relationship } \\
\text { Facial height ratio }\end{array}$ & $115 / 74$ & $116 / 74$ \\
\hline FMA $^{\circ}$ & 34 & 32 \\
\hline Manibular plane to SN plane angle & & 34 \\
\hline Occlusal plane to SN plane angle & 34 & 16 \\
\hline $\begin{array}{l}\text { Dental Relationship } \\
\text { U1 to SN }\end{array}$ & 16 & 103 \\
\hline
\end{tabular}

\begin{tabular}{|l|l|l|}
\hline IMPA $^{\circ}$ & 96 & 95 \\
\hline $\begin{array}{l}\text { Soft tissue } \\
\text { Nasolabial angle }\end{array}$ & 83 & 72 \\
\hline H line angle & 11 & 15 \\
\hline
\end{tabular}

Table 1: Pretreatment (pre) and Posttreatment (post) Cephalometric changes observed in Skeletal, Dental, and Soft Tissue Variables

\section{Conclusion}

1) The cephalometric findings in this study demonstrate that early treatment is clinically indicated for maxillary hypoplasia in skeletal class II patient.

2) Facemask with bonded rapid maxillary expander can be an effective treatment modality for maxillary hypoplasia in skeletal class II patient with minimal unwanted side effects.

\section{References}

1. McNamara JA Jr (1987) An orthopedic approach to the treatment of Class III malocclusion in young patients. J Clin Orthod 21: 598-608.

2. Kokich VG, Shapiro PA, Oswald R, Koskinen-Moffett L, Clarren SK (1985) Ankylosed teeth as abutments for maxillary protraction: a case report. Am J Orthod 88: 303-307.

3. Vachiramon A, Urata M, Kyung HM, Yamashita DD, Yen SL (2009) Clinical applications of orthodontic microimplant anchorage in craniofacial patients. Cleft Palate Craniofac J 46: 136-146.

4. da Silva Filho OG, Magro AC, Capelozza Filho L (1998) Early treatment of the Class III malocclusion with rapid maxillary expansion and maxillary protraction. Am J Orthod Dentofacial Orthop 113: 196-203.

5. Baccetti T, McGill JS, Franchi L, McNamara JA Jr, Tollaro I (1998) Skeletal effects of early treatment of Class III malocclusion with maxillary expansion and face-mask therapy. Am J Orthod Dentofacial Orthop 113: 333-343.

6. Hassel B, Farman AG (1995) Skeletal maturation evaluation using cervical vertebrae. Am J Orthod Dentofacial Orthop 107: 58-66.

7. Baik HS (1995) Clinical results of the maxillary protraction in Korean children. Am J Orthod Dentofacial Orthop 108: 583-592.

8. Alcan T, Keles A, Erverdi N (2000) The effects of a modified protraction headgear on maxilla. Am J Orthod Dentofacial Orthop 117: 27-38.

9. Kapust AJ, Sinclair PM, Turley PK (1998) Cephalometric effects of face mask/expansion therapy in Class III children: a comparison of three age groups. Am J Orthod Dentofacial Orthop 113: 204-212.

10. Tindlund RS (1989) Orthopaedic protraction of the midface in the deciduous dentition. Results covering 3 years out of treatment. J Craniomaxillofac Surg 17 Suppl 1: 17-19.

11. Franchi 1, Baccetti T, McNamara JA (2004) Postpubertal assessment of treatment timing for maxillary expansion and protraction therapy followed by fixed appliances. Am J Orthod Dentofacial Orthop 126: 555-568.

12. Melsen B, Melsen F (1982) The postnatal development of the palatomaxillary region studied on human autopsy material. Am J Orthod 82: $329-342$.

13. Cha KS (2003) Skeletal changes of maxillary protraction in patients exhibiting skeletal class III malocclusion: a comparison of three skeletal maturation groups. Angle Orthod 73: 26-35.

14. Shanker S, Ngan P, Wade D, Beck M, Yiu C, et al. (1996) Cephalometric A point changes during and after maxillary protraction and expansion. Am J Orthod Dentofacial Orthop 110: 423-430.

15. Kim JH, Viana MA, Graber TM, Omerza FF, BeGole EA (1999) The effectiveness of protraction face mask therapy: a meta-analysis. J Orthod Dentofacial Orthop 115: 675-685. 
Citation: Suryawanshi GR, Philip K, Kumar S (2014) Treatment for Maxillary Hypoplasia in Skeletal Class III Patient. Dentistry 4: 262. doi: 10.4172/2157-7633.1000262

Page 5 of 5

16. So LL (1996) Effects of reverse headgear treatment on sagittal correction in girls born with unilateral complete cleft lip and cleft palate--skeletal and dental changes. Am J Orthod Dentofacial Orthop 109: 140-147.

17. Macdonald KE, Kapust AJ, Turley PK (1999) Cephalometric changes after the correction of class III malocclusion with maxillary expansion/ facemask therapy. Am J Orthod Dentofacial Orthop 116: 13-24.

18. Takada K, S. Petdachai and M. Sakuda (1993) Changes in dentofacial morphology in skelettal Class III children treated by a modified maxillary protraction headgear and a chin cup: a longitudinal cephalometric appraisal. Eur J Orthod 15: 211-221.

19. Chong YH, Ive JC, Artun J (1996) Changes following the use of protraction headgear for early correction of Class III malocclusion. Angle Orthod 66: 351-362.
20. Ishii H, S. Morita, Y. Takeuchi and S. Nakamura (1987) Treatment effect of combined maxillary protraction and chincap appliance in severe skeletal Class III cases. Am J Orthod Dentofacial Orthop 92: 304-312.

21. da Silva Filho OG, Magro AC, Capelozza Filho L (1998) Early treatment of the Class III malocclusion with rapid maxillary expansion and maxillary protraction. Am J Orthod Dentofacial Orthop 113: 196-203.

22. Tanne K, J. Hiraga, K. Kakiuchi, Y. Yamagata and M. Sakuda (1989) Biomechanical effect of anteriorly directed extraoral forces on the craniofacial complex: a study using the finite element method. Am J Orthod Dentofacial Orthop 95: 200-207.

23. Miyasaka-Hiraga J, Tanne K, Nakamura S (1994) Finite element analysis for stresses in the craniofacial sutures produced by maxillary protraction forces applied at the upper canines. Br J Orthod 21: 343-348. 